\title{
0651 CHILD INJURY AT HOME: EXPLORING A CONNECTION BETWEEN HOUSEHOLD RULES ABOUT SAFETY, SIBLING HARM AND CHILD INJURY
}

E Alho*, C Piotrowski, G Briggs Correspondence: University of Manitoba, 33 Blossom Bay Winnipeg, Manitoba R3R2W1, Canada

\subsection{6/ip.2010.029215.651}

Child injury is the leading cause of child mortality and morbidity in Canada. Several factors that increase a child's risk of injury have been identified, including but not limited to: age, gender, type of activity and type of supervision. The present study focused on adult supervision at home. When parents are asked about commonly used injury prevention strategies, they identify teaching as a preferred tactic, yet few parents actually rely on this strategy. In addition, little is known about the role siblings play in child injury in the home. The goal of the present poster was to explore whether children's knowledge of rules pertaining to household safety and sibling harm was associated with reduced injury risk. We also investigated whether children's knowledge of household safety rules was related to their parents knowledge of these rules, and if this association was related to child injury risk. Eighty-five Canadian families with at least one child aged 6-10 years and one sibling were visited at home. Both children and one parent were interviewed. Preliminary results indicated that children endorsed $68 \%$ of household safety rules as present in their home, and that their knowledge of safety rules was significantly related to fewer minor injuries. In addition, in $66 \%$ of families children identified rules restricting or forbidding sibling harm and in these families, children experienced significantly fewer minor injuries. Directions for future research and family-based injury prevention strategies were discussed. 